\title{
OPORTUNIDADES DO MERCADO DE CRÉDITO DE CARBONO PARA USINAS SUCROALCOOLEIRAS DO BRASIL
}

\author{
CARDOSO, Chirlei Rosa ${ }^{1}$ \\ RODRIGUES, Elaine Miranda ${ }^{2}$ \\ CAMPOS, Luciana Spínpolo ${ }^{3}$
}

Recebido em: $2008-12-10$

Aprovado em: 2009-04-09

ISSUE DOI: $10.3738 / 1982.2278 .157$

\begin{abstract}
RESUMO: Com o aumento da produção e competitividade no ramo industrial e tecnológico, o clima do planeta vem passando por constantes transformações, envolvendo sérias discussões sobre o assunto, a exemplo disso, o aumento de gás carbônico lançado na atmosfera por países mais industrializados. $\mathrm{O}$ questionamento tem como relevância reverter à situação em que se encontra o mundo, envolvendo algumas das etapas que demonstram a importância do assunto no modelo atual de consumo sustentável da natureza. E a partir de negociações como essas é que se deu a origem do Protocolo de Kyoto em 1997 no Japão, que estipula metas de redução das emissões de poluição para países mais desenvolvidos, ofertando assim a possibilidade de países em desenvolvimento comercializarem emissões no Mercado de Crédito de Carbono, gerando uma nova fonte de renda. O objetivo geral dessa pesquisa foi investigar, com base na literatura, quais são as oportunidades encontradas para as empresas com ênfase nas usinas de cana de açúcar, que possivelmente será um bom segmento para investir devido à alavancagem de projetos de cogeração de energia, no intuito de diminuir os danos ambientais e aumentar sua rentabilidade, utilizando o conceito do Mecanismo de Desenvolvimento Limpo e ainda tornando o país sustentavelmente desenvolvido. Após a realização de entrevista pode-se concluir a existência de oportunidades para Usinas Sucroalcooleiras do Brasil, com expectativa do crescimento na comercialização de créditos de carbono, em virtude do aumento da demanda nacional e internacional pelo uso de energias mais limpas.
\end{abstract}

Palavras chaves: Crédito de Carbono. Mecanismo de Desenvolvimento Limpo. Protocolo de Kyoto. Usinas sucroalcooleiras.

\section{MARKET OPPORTUNITIES FOR CARBON CREDITS TO BRAZILIAN SUGAR AND ETHANOL INDUSTRIES.}

SUMMARY: Because of production and competitiveness in industry and technology, the global climate is in constant change, involving important discussions about this issue, for example, the increase of carbon dioxide released into the atmosphere by industrially countries. The questions have as objective to revert the situation, involving some steps and processes that demonstrate the importance of this discussion as an current model of sustainable use of nature. From these negotiations that Kyoto's Protocol was created, generating new income resources. The general objective of this paper was to investigate, by literature, what opportunities are been created to the firms, specially of cane sugar cultivation - an important segment to invest cause of the energy co-generation projects - with the purpose to reduce the environmental damage and increase the incomes, by the concept of Clean Development Mechanism. After an important process of interviews we can conclude that there are opportunities to the firms of cane sugar process and cultivation, because of the national and international demand by clean energy use.

\footnotetext{
1 Bacharel em Administração - Agronegócios pela FFCL/FE. E-mail: chirleirc@ yahoo.com.br Bacharel em Administração - Agronegócios pela FFCL/FE. E-mail: laininhamig@ yahoo.com.br Mestre em Administração de Organizações - FEA-RP/ USP. Prof. FFCL/FE - orientadora deste trabalho.
} 
Keywords: Carbon Credits. Clean Development Mechanism. Kyoto Protocol. Sugar and Ethanol industries.

\section{INTRODUÇÃO}

Com o passar dos anos, o clima do planeta vem se modificando gradativamente, e um dos principais motivos é a interferência do homem relacionado ao avanço tecnológico e industrial. Devido ao constante aumento da poluição por meio das indústrias e meios de transportes que utilizam combustível fóssil, ocorreu na elevação de gases nocivos que originam efeito estufa, prejudiciais ao meio ambiente, agravandose ainda mais o aumento da temperatura do planeta.

Países de todas as partes do mundo preocupados com as consequiências do aumento da temperatura buscaram alternativas de como reverter essa situação, e dentre os meios apresentados pelas partes representantes, houve o surgimento do Mecanismo de Desenvolvimento Limpo (MDL), um mecanismo de Flexibilização do Protocolo de Kyoto, que determina a possibilidade de países industrializados, que detêm certos limites de emissões, poderão negociar com países em desenvolvimento que são livres de emissões.

No intuito de amenizar a situação climática, houve então o surgimento de oportunidades para países como o Brasil, com enfoque no setor de energia renovável por meio do bagaço da cana e do etanol no setor sucroalcooleiro, diminuindo o $\mathrm{CO}_{2}$ (dióxido de carbono) na atmosfera e disponibilizando ao país o direito de vender créditos de carbono para outros países, colocando o país dentre os maiores ofertantes do Crédito de Carbono, alcançando o terceiro lugar na disponibilização de emissões do Mercado de Carbono.

Contudo, analisando a inserção desses projetos no comércio de carbono, há a compreensão dos aspectos referentes à ampliação do desenvolvimento sustentável, na busca de novas formas de captação de recursos financeiros e melhoria na imagem da empresa no mercado, não deixando de enfatizar quais as perspectivas futuras quanto à atuação destes projetos no primeiro período de compromisso e no pós 2012, referente ao término do Protocolo.

A proposta de construção deste trabalho baseia-se na seriedade de se investigar como o Brasil estará a caminho do crescimento de uma economia mais forte tendo por 
base o aproveitamento de suas ferramentas ambientais como alternativa na busca do desenvolvimento sustentável, colaborando para a redução de emissões dos gases do efeito estufa (GEE), que gera o aquecimento global.

Ao longo dos anos o planeta está, a cada dia, mais quente, devido ao alto teor de poluição na atmosfera (CHOHFI et al, 2008), e o que mais preocupa os especialistas e a população em geral, é como a situação pode ser revertida. Mas o que precisa ser esclarecido é como estes projetos geram oportunidades em países como o Brasil, desenvolvendo seu mercado por meio de energias limpas e renováveis e projetos de eficiência energética que colaboram com ampliação do desenvolvimento sustentável (PIVA; BAITELO, 2007).

Por meio de projetos do MDL, como a co-geração de energia, biocombustíveis como o etanol, propiciará o aumento da inclusão social, levando em conta além das características de práticas agrícolas, também a atividade no campo e aspectos naturais como oportunidades empresariais no aspecto sócio-econômico do país (RIBEIRO, 2007), visando sua importância para o desenvolvimento do agronegócio brasileiro.

O Mercado de Crédito de Carbono tem se tornado uma fonte importante para a captação de recursos financeiros para empresas de Agronegócio, principalmente para o Brasil, fazendo com que as empresas tenham uma renda extra para a complementação de seu fluxo de caixa. Além disso, as empresas podem melhorar a sua imagem no mercado, ganhando força por meio do Mercado de Crédito de Carbono com o denominado "Marketing Verde", ou simplesmente, responsavelmente correta em termos ambientais e sociais.

Tendo por base o referencial teórico o problema de pesquisa apresenta-se da seguinte forma: Como as usinas de cana de açúcar estão colocando em prática os projetos que visam à diminuição do aquecimento global e, consequentemente, trazendo para si e para o país uma nova forma de rentabilidade financeira, captação de recursos renováveis e colaborando para ao desenvolvimento sustentável e sócio-econômico ao país?

O objetivo da presente pesquisa é analisar como mercado de crédito de carbono pode ser uma oportunidade para o setor sucroalcooleiro, e assim verificar as possibilidades do Brasil se tornar um dos líderes deste mercado, além da promoção do desenvolvimento sustentável e econômico do país.

Para alcançar o objetivo geral proposto, foram definidos os seguintes objetivos específicos: 
i) Investigar a formação do mercado de crédito de carbono;

ii) Possibilidades geradas ao setor sucroalcooleiro por meio deste mercado.

\section{METODOLOGIA}

A metodologia empregada neste trabalho está fundamentada em pesquisas bibliográficas que retratam o assunto estudado, incluindo pesquisa de campo que contribuirá na obtenção de informações precisas quanto ao estudo proposto.

Dessa maneira, pode-se afirmar que trata-se de uma pesquisa qualitativa. Este tipo de pesquisa possibilita a interpretação de opiniões e expectativas dos indivíduos, ou seja, informações difíceis de serem obtidas por uma pesquisa quantitativa.

Os estudos dessa natureza são capazes de descrever a complexidade de um problema, abranger e classificar processos dinâmicos vividos por grupos, e também podem contribuir no processo de mudança de um grupo, além de permitir a compreensão das peculiaridades de conduta dos indivíduos.

Para concretização dos objetivos desta pesquisa, o método adequado, dada às características da pesquisa de campo que já foram apresentadas é designada pela realização de entrevistas, visto que este método de trabalho permite a descoberta de situações que não seriam encontradas de outra forma, em que análises e dedução são realizadas por afinidade de situações (YIN, 2005).

Assim sendo, também foi realizada uma pesquisa de campo em uma empresa de consultoria em comercialização no mercado de crédito carbono.

\section{REFERENCIAL TEÓRICO}

A produção de cana de açúcar no Brasil teve início em meados do século XIV (período colonial), tornando-se maior produtor mundial de cana de açúcar do mundo no século XVII, em um ciclo que permeou por 150 anos (RODRIGUES; ORTIZ, 2006). Na década de 1970, com a crise do petróleo surgiu um novo ciclo, através do Programa Nacional do Pró-Álcool, que possibilitou a melhoria tecnológica voltados para o plantio e uso mais eficiente da cana de açúcar.

Entretanto, o ciclo do Pró-Álcool teve seu término na década de 1980, devido uma crise de confiabilidade do setor sucroalcooleiro e do governo, originado pelo não atendimento do mercado nacional no respectivo período. A partir dos anos 2000, a única 
medida restante do programa, era a adesão de $25 \%$ de álcool anidro à gasolina (RODRIGUES; ORTIZ, 2006).

Com o auxílio do programa pode-se dizer que ampliou-se a especialização em tecnologia de produção no Brasil, passando a ser reconhecido mundialmente como o maior produtor de etanol e açúcar, devido a sua eficiência de produtividade, condições climáticas favoráveis, mão-de-obra barata e assim menores e melhores custos de produção.

Atualmente o país encontra-se em expansão comercial, tanto para o comércio de etanol (considerado biocombustível) quanto na produção de açúcar e também em um outro fator que envolve projetos, por meio da captação de gases nocivos ao meio ambiente no mercado mundial de crédito de carbono (RODRIGUES; ORTIZ, 2006). Este novo fator de crescimento econômico traz novas oportunidades para o país, que possibilita o desenvolvimento sócio-econômico para o Brasil, originando a inserção de projetos que promovem o desenvolvimento sustentável onde as empresas estão inseridas.

Orientado ao constante avanço tecnológico e industrial, o planeta vem passando por constantes transformações, principalmente com relação ao clima que, por sua vez, está em desequilíbrio devido ao rápido crescimento das indústrias nos centros urbanos, aumentando gradativamente o acúmulo de gases nocivos, que geram a ocorrência do efeito estufa, o constante crescimento do buraco da camada de ozônio, chuvas ácidas, não obstante, o aquecimento global (CHOHFI et al, 2008).

Com essa constante transformação, as indústrias estão sendo obrigadas, por meio do Protocolo de Kyoto, a buscarem formas diferentes de sustentabilidade energética, ou seja, visam novas formas de captação de energia que não degradam tanto o Meio Ambiente. Mesmo com problemas ocorridos pela rapidez no crescimento de pólos indústrias foram originadas chances de inserção neste mercado para países em desenvolvimento como o Brasil, que por meio de sua fonte de energia basicamente limpa, proporcionará a abertura de negociações no mercado de crédito de carbono com países que necessitam alcançar suas metas até 2012 (CHOHFI et al, 2008).

Por meio desse mercado, países em desenvolvimento como o Brasil, que reduzem as emissões de gases responsáveis pelo efeito estufa ou absorvem carbono da atmosfera, gerarão créditos que poderão ser usados por países desenvolvidos para atingir as metas estabelecidas pelo Protocolo de Quioto (DELGADO, 2006). 
Atualmente o país encontra-se em inserção cada vez maior de projetos no mercado que captam os gases nocivos ao meio ambiente.

Segundo Chohfi et al (2008) e Biodiesel (2008) as oportunidades destacadas para o Brasil baseiam-se em projetos que ganharam destaque nas negociações de crédito de carbono, dentre eles estão inseridas as indústrias sucroalcooleiras com projetos de co-geração ${ }^{4}$ de energia elétrica através do bagaço da cana e substituição de combustíveis fósseis por biocombustíveis como o etanol.

O potencial para as indústrias sucroalcooleiras está estimado em 1,5 bilhões de litros ao ano para o consumo interno, de uma demanda estimada de 25 bilhões de litros para 2013, juntamente com uma oferta de 30 bilhões de litros de etanol para 2015, agregando o valor à exportação (RODRIGUES; ORTIS, 2006).

Segundo Santos (2005), o mercado de álcool é um dos setores de comercialização que têm maior potencial de crescimento para os próximos anos, pois com a constante preocupação com o meio ambiente, o biocombustível e a co-geração de energia no mercado de crédito de carbono são consideradas boas alternativas de redução de gases que causam o efeito estufa (GEE), sendo denominados projetos inseridos nos Mecanismos de flexibilização ${ }^{5}$, associados ao Protocolo de Kyoto.

O protocolo de Kyoto é um contrato que tem por objetivo o cumprimento de metas para a diminuição das emissões de gases que promovem o efeito estufa, incluindo principalmente países desenvolvidos, proporcionando, aos países em desenvolvimento, formas de rendimento, que causam menores impactos ao meio ambiente (FREITAS, 2008).

Contudo o mercado de crédito de carbono dispõe de outras formas de negociações, por meio do Mercado Voluntário que disponibiliza preços de comercialização menores às empresas emissoras de gases poluentes.

O surgimento de mecanismos de desenvolvimento limpo (MDL), ou seja, um instrumento de flexibilização criado no intuito de auxiliar na redução do GEE, originouse devido à apresentação de uma proposta do Brasil à Convenção Quadro das Nações

A co-geração de energia baseia-se na capacidade das usinas em criar energia através do bagaço ou palha da cana-de-açúcar, no qual o excedente poderá ser comercializado na busca de uma nova captação de recursos financeiros.

5 Os Mecanismos de Flexibilização são instrumentos que disponibilizam por meio de projetos de captação de gases nocivos ao meio ambiente, formas de comercialização entre os países do mundo. Os

Instrumentos de Flexibilização são três:

- Joint Implementation - JI (Implementação Conjunta);

- Emissions Trade - ET (Comércio de Emissões);

- Clean Development Mechanism - CDM (Mecanismo de Desenvolvimento Limpo - MDL). No qual o mais comum é o Comercio de Emissões (BERTUCCI, 2006 apud Bassetto et al, 2006). 
Unidas sobre Mudança do Clima (CQNUMC), que visa a criação de projetos que capturam gases nocivos ao meio ambiente, originando o mercado de crédito de carbono (BIODIESEL, 2008).

Uma das maiores dificuldades encontradas pela aprovação dos projetos é a falta de subsídios em pesquisas, que possibilitaria adoção de métodos a serem utilizados pelas empresas para obtenção de crédito de carbono, pois o custo da operação comercial dos projetos é relativamente alto, girando em torno de US\$150 mil, além de oferecer um alto risco ao investidor (BIODIESEL, 2008).

Isso significa que, até a aprovação dos projetos, é demandado certo tempo e custo elevado, o que torna ainda mais difícil a sua incorporação nas empresas que optam por trabalhar com mercado de crédito de carbono.

A comercialização do crédito de carbono é fundamentada pelos projetos que seqüestram gases ou que transformam materiais antes nunca usados em uma nova forma de capitação de poluentes como o biodiesel, reflorestamento, criação de energia renovável como o carvão vegetal de siderurgias, co-geração de energia do bagaço da cana de açúcar e etanol das usinas sucroalcooleiras, palha de arroz, reciclagem de lixo e manejo de dejeto de animais ${ }^{6}$, entre outros projetos que estão sendo criados no intuito de participarem das negociações no mercado de capitais (BIODIESEL, 2008).

O mercado de crédito de carbono é negociado em contratos futuros na Bolsa de Mercadorias e Futuros (BM\&F), por meio do Mercado Brasileiro de Reduções de Emissões (MBRE) ${ }^{7}$, cujos certificados de redução atuam de maneira que países que são obrigados a diminuírem suas emissões (recebendo bônus ou cotas que podem ser negociados), de acordo com seu grau de poluição. Respectivamente, cada cota ou bônus a ser negociada em bolsas de valores, representam uma tonelada de carbono equivalente negociável, cotado em dólares (DELGADO, 2008).

Uma forma encontrada de viabilizar esses projetos está relacionada às modalidades diferentes em projetos de baixa escala e de baixa renda, com metodologias simplificadas, proporcionando o incentivo de pequenos empresários que buscam se beneficiarem do mercado de crédito de carbono, principalmente por meio de cooperativas com a ajuda do BNDES (Banco Nacional de Desenvolvimento Econômico

\footnotetext{
$6 \quad$ O gás metano $\left(\mathrm{CH}_{4}\right)$ é um dos gases que mais poluem o meio ambiente e logo em seguida o gás carbônico $\left(\mathrm{CO}^{2}\right)$.

7 O MBRE é uma plataforma de títulos negociáveis na BM\&F, que representa um instrumento de incentivo às negociações no mercado de capitais para a criação de um banco de projetos de MDL no Brasil (BIODIESEL, 2008).
} 
e Social) em linhas de crédito criadas para esse fim (DELGADO, 2008 e BIODIESEL, 2008).

O desenvolvimento sustentável, por sua vez, está incluso no MDL, e o Brasil faz parte dos países a se beneficiarem de tal aspecto; assim, os projetos terão que garantir a geração de emprego e renda, benefícios sociais e ambientais.

Segundo Nascimento (2007), a sustentabilidade ambiental é um fator de extrema importância nos tempos atuais, devido ao alto grau de poluição emitido pelas empresas. Estas são obrigadas a buscarem novas técnicas de captação de recursos, conciliando a economia com a preservação ambiental, originando o desenvolvimento sustentável, o que torna este incidente um fator de competitividade mercadológico, pois além de cuidar do meio ambiente e trazer benefícios à sociedade, torna-se uma estratégia de mercado para as empresas que buscam uma oportunidade de crescimento organizacional, como o exemplo, das usinas sucroalcooleiras.

A proposição da pesquisa refere-se à nova sistemática de rentabilidade econômico-financeira que as usinas de cana de açúcar têm conseguido por meio das práticas dos projetos que visam à diminuição do aquecimento global, além de conseguirem a captação de recursos renováveis e colaborando para ao desenvolvimento sustentável e sócio-econômico ao país.

De acordo com Observatório do Clima (2002), empresas que visam à adoção de negociações do mercado de crédito de carbono terão de analisar se o projeto atenderá às necessidades quanto à implementação do desenvolvimento sustentável, ou seja, a geração de renda e empregos para a economia local, fontes novas de energia limpa, geração de novos negócios; evidenciando de fato, que as empresas que demonstram preocupação com esta tendência poderão negociar seus créditos de carbono.

No entanto, o não cumprimento dos deveres pela responsabilidade social, ambiental e econômica, não haverá a aprovação do projeto proposto quanto ao ingresso no novo tipo de comércio mundial, independente do projeto que visa à redução do Gás Carbônico $\left(\mathrm{CO}_{2}\right)$ na atmosfera.

Para as usinas sucroalcooleiras que visam à implementação de projetos voltados para o crédito de carbono, devem estar atentas às formas de uso da terra e a biodiversidade local, mão-de-obra qualificada e legalizada; melhoria de tecnologia de colheita (visando a não queimada dos canaviais); redução da poluição dos rios e afluentes; não degradação do meio ambiente onde está inserida; desenvolvimento e geração de emprego para a população local (RODRIGUES, 2006; ORTIS, 2006). 
Assim, suprindo todas essas necessidades e ainda atendendo aos requisitos específicos quanto à elaboração dos projetos no âmbito do mercado de carbono, as usinas poderão usufruir dos ganhos financeiros e melhoria da imagem no mercado, gerados pela implantação do mesmo. E uma das expectativas do mercado de carbono para as usinas, além da co-geraçao do bagaço da cana, está nas particularidades do aumento do consumo do etanol em todo o mundo.

No caso do etanol (biocombustível) em sua capacidade de utilização, a emissão é de $0,248 \mathrm{~kg}$ de $\mathrm{CO}_{2}$ equivalente por litro na atmosfera, comparando-o às emissões da produção e o consumo de 1 litro gasolina que se refere a 2,74kg de $\mathrm{CO}_{2}$ equivalente, a utilização do etanol representa a diminuição de emissão de poluentes na atmosfera de 2,43 $\mathrm{kg}$ de $\mathrm{CO}_{2}$ equivalente por litro de etanol na substituição da gasolina (MACEDO, 2004 apud RODRIGUES; ORTIZ, 2006).

Além disso, ainda há a utilização do bagaço da cana de açúcar na geração de energia para o próprio fornecimento das usinas e venda dos excedentes, gerando o comércio de créditos e carbono das usinas sucroalcooleiras.

Assim sendo a busca pelo domínio de mercado o etanol terá um papel cada vez mais importante no Brasil e no mundo como biocombustível, proporcionando uma grande corrida pela rentabilidade e lucratividade, no qual vários projetos que estão em andamento, envolvendo questões socioeconômicas e ambientais.

De acordo com o Ministro de Minas e Energia, Sr. Silas Rondeau, o uso do etanol de 1970 a 2006, como substituto dos derivados do petróleo como a gasolina rendeu ao Brasil uma economia de 1,09 bilhões de barris de petróleo, evitando a emissão de 615 milhões de toneladas de dióxido de carbono na atmosfera (RODRIGUES et al, 2006). No entando outra forma de oportunidade como a co-geração de energia através do bagaço da cana de açúcar poderá chegar a ser uma fonte de energia elétrica no país, proporcionando o desenvolvimento em vários aspectos como sócio-econômico e ambiental.

Com relação aos riscos encontrados no mercado de crédito de carbono independente de qual ramo de projeto da empresa (co-geração, reflorestamento, florestamento, biomassa etc.), um dos principais riscos encontrados esta relacionado ao risco de não existência do mercado pós 2012, como fundamenta Lecocq; Capoor (p. 14, 2005 apud CONEJERO; NEVES 2007):

O risco de não-existência do mercado pós-2012, é a principal limitação para o sucesso do Protocolo de Quioto. Se não há um segundo período de cumprimento, não há incentivos para os países reduzirem emissões, já que as 
penalidades pelo não-cumprimento das metas é a não-participação no mercado em um segundo período de cumprimento.

No entanto existem outros riscos inseridos no mercado de crédito de carbono como: riscos de países em desenvolvimento com metas para reduzir emissões, risco de não validade das Reduções Certificadas de Emissões (RCE's) no mercado Europeu; risco de não obtenção do registro no MDL; risco da não aprovação da metodologia da linha de base e monitoramento; risco de não desempenho do projeto conforme previsto no momento da elaboração do contrato e o risco de quebra contratual (CONEJERO; NEVES, 2007). Estes riscos fomentam a dificuldade de inserção de projetos no mercado, com incertezas ligadas à aprovação de projetos do MDL.

Segundo Conejero, Neves (2007), o tempo de duração das transações do mercado de crédito de carbono para projetos energéticos pode ser de 10 a 21 anos (três ciclos de sete anos) e para projetos florestais de 20 a 60 anos (com dois ciclos de 30 anos), no qual a repetições de transações desses projetos possibilitam a adaptação neste novo mercado.

Para que os projetos entrem em vigor são necessários vários passos a serem seguidos, conforme cita Conejero (2006):

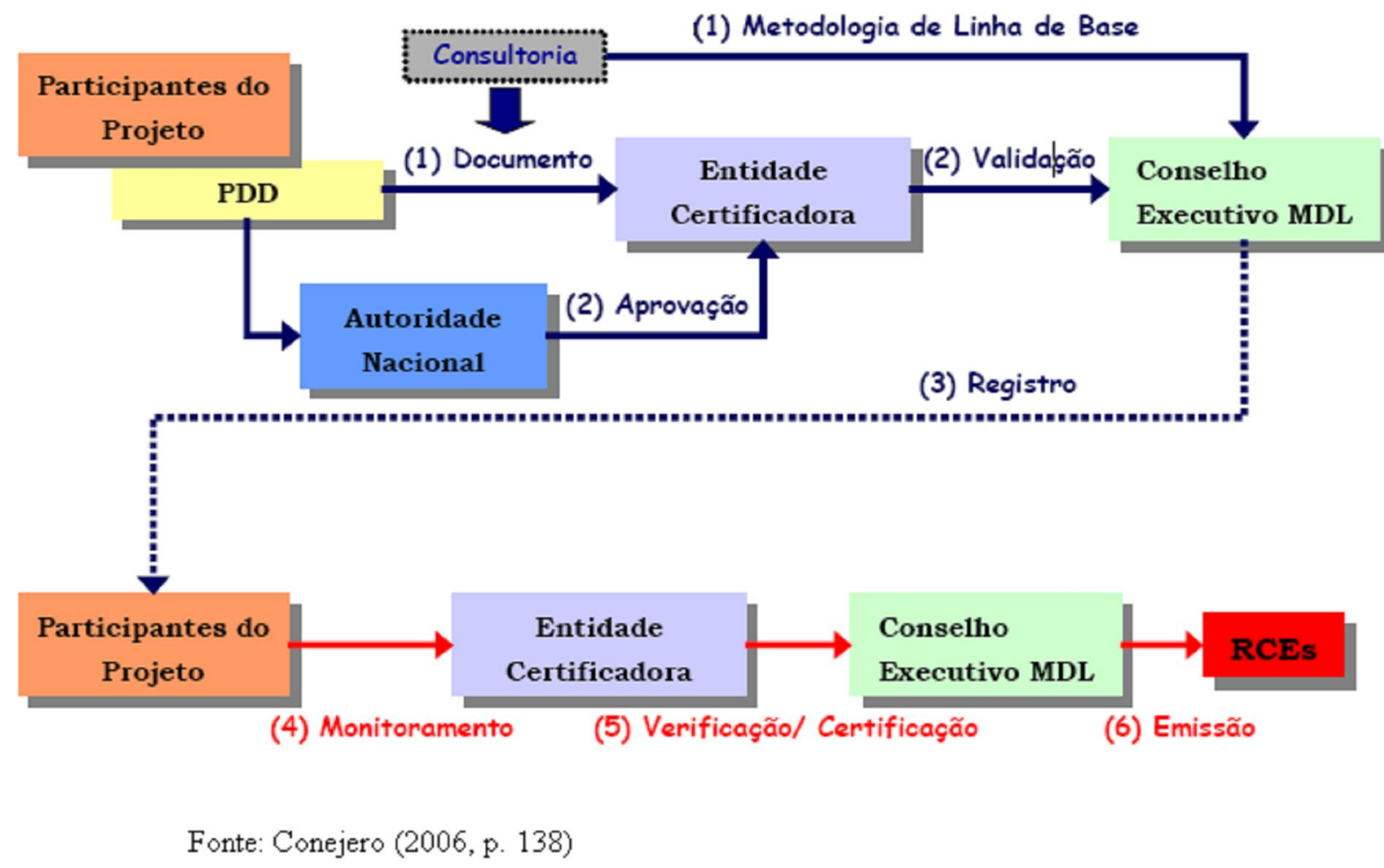

FIGURA 1: Procedimentos Necessários para obtenção de RCEs. 
Segundo Moreira;Giometti (2008), através da Figura 1, os passos a serem seguidos para a concepção do relatório de certificação, é submetido ao Conselho Executivo pela Entidade Operacional Designada (EOD), que poderá ou não conceder uma solicitação para as emissões de RCE's em um período de quinze dias após a solicitação, estando apta a revisão caso solicitado pelo Conselho Executivo. Depois de todos os processos o Administrador de Registro do MDL emite a quantidade devida de RCE's a serem negociadas pelas partes no mercado de carbono (BRASIL, 2005 apud MOREIRA; GIOMETTI, 2008).

De acordo com o Ministério da Ciência e Tecnologia do Brasil (2008):

O relatório de Validação não deve constar nenhuma ressalva ou ação corretiva pendente [...] só ser emitida pelo Governo Brasileiro após a Validação [...], deverá obter a aprovação por escrito da participação voluntária da $\mathrm{AND}^{8}$ do Brasil, inclusive a confirmação de que o Projeto contribui para que o país atinja o desenvolvimento sustentável.

As empresas que visam integrar nesse novo mercado devem estar atentas durante o período de aprovação, aspectos quanto às Linhas de Base e Adicionalidade e monitoração dos projetos a serem inseridos para verificação das metas de $\mathrm{CO}_{2}$ a serem cumpridas (CONEJERO, 2006).

Segundo Conejero (2006) e Leme; Cunha; Walter (2008), linha de base é o cenário de referência que representa as emissões que ocorreriam na ausência do projeto a ser inserido no mercado, servindo de base para analisar e verificar a adicionalidade e quantificar as emissões de RCE's do projeto do MDL. Já o principio de adicionalidade compreende na identificação da quantidade de redução ou remoção dos gases que promovem o efeito estufa de forma adicional, apresentadas no projeto, sendo estas mensuráveis, reais e de longo prazo (LEME; CUNHA; WALTER, 2008).

Ao analisar qual setor está em destaque no âmbito do mercado de crédito de carbono, logo visualiza-se que a grande maioria baseia-se no setor de energia renovável, como mostra a figura a seguir:

$8 \quad$ AND (Autoridade Nacional Designada), no qual se refere à Comissão Interministerial de Mudança Global do Clima (CIMGM), cujo faz a carta de autorização do projeto para os participantes nacionais do MDL (Ministério da Ciência e Tecnologia do Brasil, 2008). 


\section{Número de Projetos Brasileiros por Escopo Setorial}
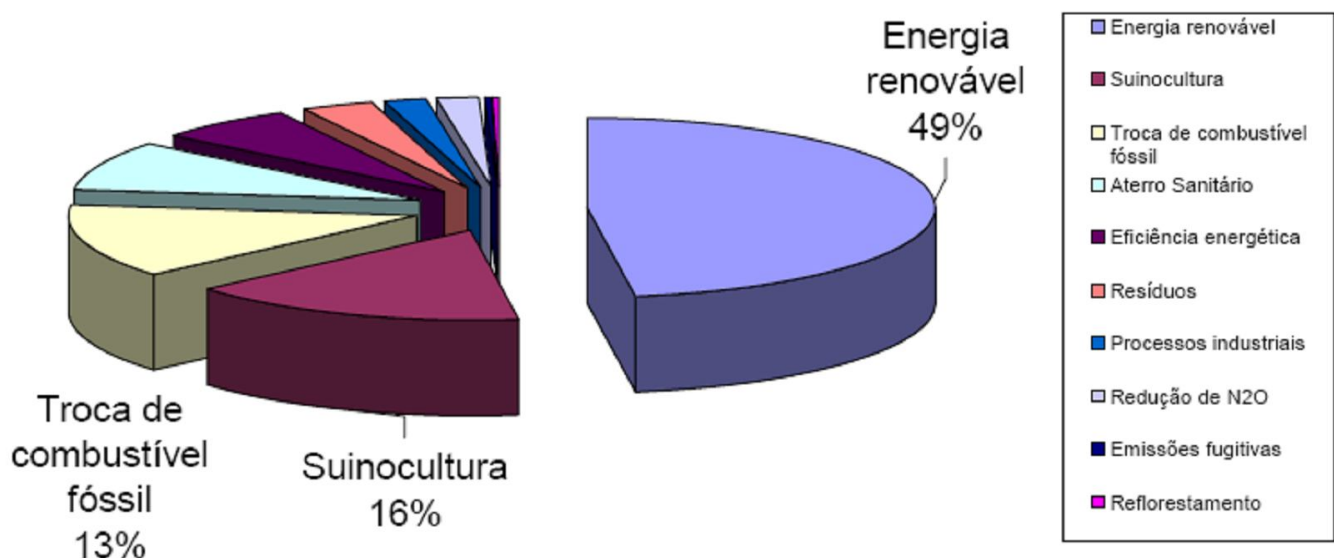

Fonte: Brasil. Ministerio da Ciencia e tecnologia (2008)

GRÁFICO 1: Distribuição das atividades de projeto no Brasil por escopo setorial

Pode-se afirmar que as usinas, através do aproveitamento do bagaço de cana de açúcar, assim como outras empresas do setor de energia renovável, estão na liderança comercial de inserção de projetos no mercado de crédito de carbono do Brasil. No total são 141 projetos de energia renovável, registrados no Conselho Executivo, cujo o Brasil alcança o terceiro lugar do total de 1.092 projetos existentes já registrados, somados aos projetos de co-geração de energia (BRASIL, 2008).

No entanto a capacidade instalada de co-geração de biomassa é de $32 \%$ do bagaço da cana e quase alcançando a mesma média das termoelétricas com 36\%, como mostra a figura a seguir: 


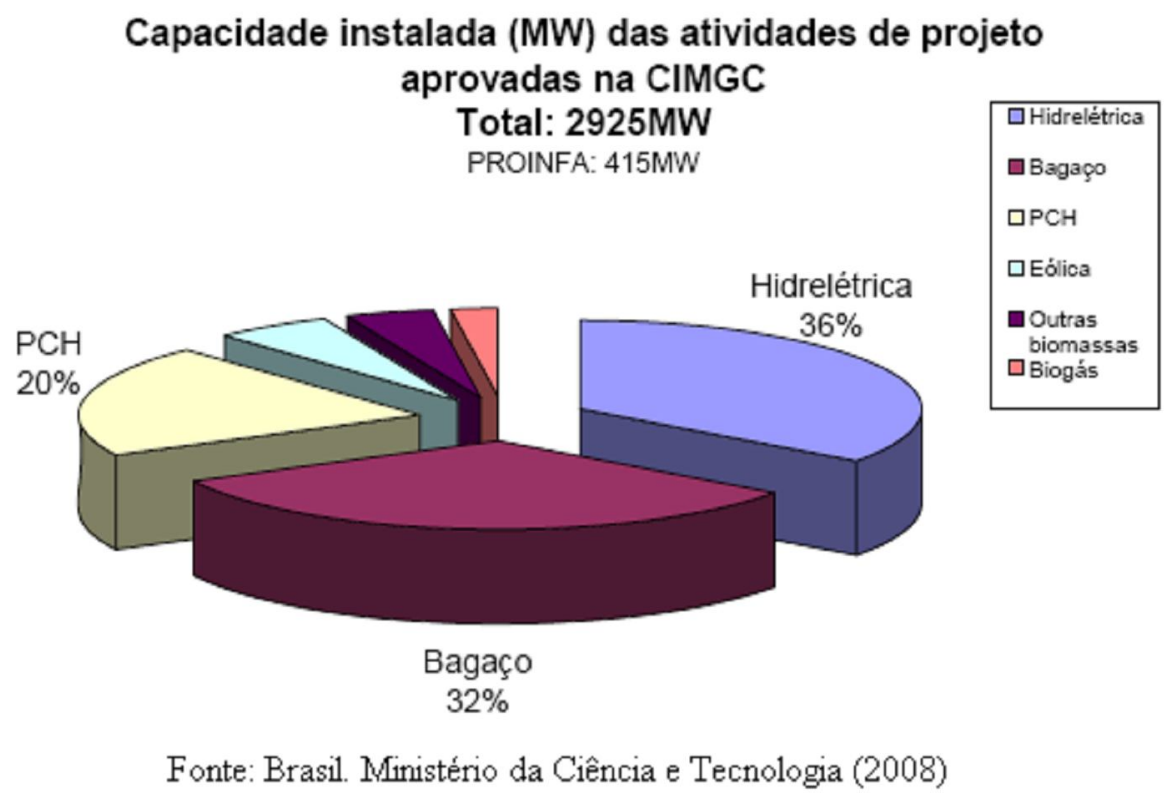

GRÁFICO 2: Capacidade instalada (MW) das atividades de projeto aprovadas na CIMGC

Atualmente o volume de créditos negociados pelo Brasil é de 158.178.820 to $\mathrm{CO}_{2}$, referente a todos os setores, de um total de 1.810.336.291 mundial. Já o estado de São Paulo, particularmente, está na liderança nos desenvolvimentos de projetos de MDL com 21\%, seguido logo após por Minas Gerais com 13\% (BRASIL, MINISTERIO DA CIENCIA E TECNOLOGIA, 2008).

Segundo o Ministério da Ciência e Tecnologia (2008), existem 29 projetos de energia renovável de usinas sucroalcooleiras, aprovados pela CIMGC (Comissão Interministerial de Mudança Global do Clima - AND do Brasil), tendo a existência de 2 projetos com ressalva para aprovação no Conselho Executivo e 1 projeto para na fase de revisão, totalizando 32 projetos para a co-geração de energia limpa no âmbito do Mercado de Crédito de Carbono.

Um dos motivos que levaram as Usinas a interagirem neste mercado é a possibilidade de captação de recursos financeiros para a geração de fluxo de caixa, tomado como incentivo do Protocolo para captação e diminuição do $\mathrm{CO}_{2}$ na atmosfera, inclusive a melhoria da imagem da empresa no mercado interno e externo, denominado Marketing Verde. 


\section{PESQUISA DE CAMPO DA AMBIO FINANÇAS AMBIENTAIS.}

Para a pesquisa de campo foram realizadas entrevistas utilizando questionários com uma empresa de Consultoria do ramo do MDL, cujo trabalho está focado em auxiliar as empresas na geração de projetos para a aprovação da AND.

$\mathrm{Na}$ pesquisa identificou-se quais as oportunidades e riscos envolvidos na implantação do projeto, potencial de comercialização de créditos de carbono voltados para as usinas e perspectivas futuras com relação ao pós-2012.

Os dados levantados pela AMBIO Finanças Ambientais, identificam que o mercado está aquecido com significativo preço de negociação em torno de \$20 euros por tonelada de crédito de $\mathrm{CO}_{2}$, gerando uma oportunidade para as usinas obterem fontes de receita em moeda forte (euros) e usar esses recursos para financiar o desenvolvimento de um projeto de geração de energia limpa.

Para se iniciar um processo de implementação dos projetos a serem inseridos pelas empresas do setor, conforme discorrido ao longo deste estudo, incluem custos de consultoria para levar o projeto durante todo o processo, custos da auditoria e custos de registro na ONU (Organização das Nações Unidas), podendo chegar a \$60.000 euros.

Contudo com o alavancamento do consumo do etanol, além do surgimento de propostas de energias renováveis, para os projetos como a co-geraçao por meio do bagaço da cana espera-se um aumento do volume de etanol negociado internacionalmente, por ser um combustível limpo, ajuda países industrializados com compromisso de Kyoto a atingirem suas metas de redução de emissão. A co-geração é um segundo negócio dentro das usinas, correspondendo por cerca de $10 \%$ do faturamento desta.

Analisando o potencial de mercado de crédito de carbono das usinas de cana de açúcar no Brasil no que se refere à co-geração, as expectativas representam cerca de 5\% no preço de venda da energia. No entanto uma desvantagem encontrada pelo setor é que a geração de energia está limitada ao período de safra de 220 dias.

Com relação ao parâmetro de atuação do setor Sucroalcooleiro atualmente em questões estratégicas de comercialização, ou seja, atuação no MDL ou no Mercado Voluntário, o primeiro é o mais utilizado, em virtude da relevância dos projetos em usinas para a geração de crédito de carbono no Brasil. 
O volume de créditos de carbono negociados pelas indústrias sucroalcooleiras, baseia-se em um volume anual, mas para perspectivas futuras, espera-se que se emitam cinco milhões de créditos até 2012.

As perspectivas futuras das usinas de cana de açúcar referente ao Pós-Kyoto, ou seja, referente ao término do primeiro período de contrato em 2012, segundo o entrevistado, o mercado se mantém bastante cauteloso. Espera-se que o mercado continue, podendo criar divisões regionais, entretanto a cadeia produtiva da cana ainda não possui dados concretos sobre os níveis de comercialização.

Ao analisar as fragilidades encontradas pelo setor sucroalcooleiro no mercado de crédito de carbono, há uma séria necessidade de demonstrar a importância dos créditos de carbono no momento da tomada de decisão para investir em uma planta de cogeração, como já explicitado anteriormente existem vário custos envolvidos.

Além disso, há a ameaça no que tange a volatilidade do mercado de carbono, na dificuldade de regulação do governo quanto ao fator de emissão da rede elétrica e nas constantes atualizações da metodologia que deve ser seguida para o registro do projeto.

\section{CONSIDERAÇÕES FINAIS}

Ao analisar o contexto teórico e as informações obtidas pela pesquisa de campo, pode-se afirmar que o setor sucroalcooleiro terá chances de avançar cada vez mais neste novo segmento de mercado, principalmente pelo aumento da eficiência na co-geração e o do consumo do etanol, cujo segmento de energia renovável é o de maior destaque no âmbito do MDL no Brasil e no mundo.

Contudo, devem-se levar em consideração os riscos envolvidos as perspectivas futuras quanto ao pós 2012, pois não se sabe ao certo ainda quais serão as discussões quanto à tomada de decisões das partes envolvidas às questões climáticas referente a este novo mercado, mas com relação às negociações até o fim do primeiro período é de importante relevância a disponibilidade de captação de recursos financeiros.

Os riscos referentes à tomada de decisão quanto à implementação, devem atender a todos os requisitos para a aprovação do projeto, estimando-se os possíveis custos de implantação dos mesmos e analisando a participação do governo dentro deste novo segmento de mercado. 
No entanto, o mercado atual está em alta, disponibilizando aumento no faturamento das empresas inseridas no MDL, devido à valorização do preço dos produtos "limpos" inseridos no mercado, a exemplo do etanol, consequentemente melhorando a imagem da empresa no âmbito da responsabilidade social e ambiental, promovendo ainda mais a ampliação do desenvolvimento sustentável local e o aumento da competitividade mercadológica Nacional e Mundial por meio do Mercado de Crédito de Carbono.

Os projetos respectivos ao setor de energia renovável, como exemplo do setor sucroalcooleiro, interferem de maneira positiva na economia do país, originando assim, o fortalecimento do Brasil equiparado aos países com menos chances do melhor aproveitamento dos recursos naturais, aumentando a empregabilidade de mão-de-obra nas empresas preocupadas com o desenvolvimento sócio-econômico local e contribuindo de forma construtiva para a diminuição do agravamento do aumento da temperatura do planeta.

Inclusive com a possibilidade de inserção de novos projetos no âmbito do MDL, há a possibilidade de maior captação de recursos financeiros para as empresas e para o Brasil, o que acarreta em um aumento de maior disponibilidade da circulação da moeda nacional dentro do país, colaborando para o fortalecimento da economia nacional.

Contudo, pode-se concluir que há a existência de oportunidades e ameaças neste novo mercado, incluindo participantes de todos os níveis de investimentos, envolvendo desde pessoas relacionadas à mão-de-obra operacional nas usinas e empresas especializadas na inserção de projetos no âmbito do MDL como consultorias, a exemplo da AMBIO Finanças Ambientais. Além de prover oportunidades para comunidades locais, investidores estrangeiros e nacionais, trazendo resultados relevantes à diminuição do aquecimento global, melhoria econômica e social local e da nação, melhor aproveitamento dos recursos naturais utilizados na geração de energia renovável ou outros setores do MDL e o desenvolvimento da sustentabilidade do país anfitrião.

Contudo, foram levantadas algumas limitações de estudos referentes à elaboração do trabalho científico ao analisar o mercado de crédito de carbono como variação de preço do $\mathrm{CO} 2$ negociado por ser negociado em Bolsa de Valores, dificuldade de reter dados de Usinas Sucroalcooleiras.

Referente ao estudo das análises sugeridas no trabalho científico sobre as oportunidades do mercado de crédito de carbono, propostas para outras análises são 
sugeridas, de acordo a proporcionar um estudo que possa compreender mais a fundo este novo mercado como: Estudar mais a fundo a viabilidade para pequenos produtores rurais, analisar o possível aumento de projetos nesse ramo de mercado, analisar as possibilidades de continuação de projetos no Pós - 2012.

Por meio de estudos mais profundos com relação à compreensão deste novo mercado, será possível estimular ou não a inserção de projetos no âmbito do MDL, tanto para pequenos produtores como para grandes empresas, a fim de ambos interagirem com esta nova oportunidade de mercado.

\section{REFERÊNCIAS}

BASSETTO, L. I. et al. Crédito de carbono: uma moeda ambiental como fator de motivação econômica. Disponível em: http://www.pg.cefetpr.br/ppgep/Ebook/ebook2006/Artigos/16.pdf . Acesso em: 06 mai 2008.

BIODIESELBR (Brasil) (Ed.). Credito de Carbono - MDL. Disponível em: http://www.biodieselbr.com/credito-de-carbono/mdl/index.htm . Acesso em: 07 mai 2008.

BRASIL. Ministério da Ciência e Tecnologia (Ed.). Status atual das atividades de projeto no âmbito do Mecanismo de Desenvolvimento Limpo (MDL) no Brasil e no mundo. Disponível em: http://www.mct.gov.br/index.php/content/view/30318.html . Acesso em: 29 jul. 2008.

CHOHFI, F. M.; DUPAS, F. A.; LORA, E. E. S. Balanço, análise de emissões e seqüestro de $\mathrm{CO2}$ na geração de eletricidade excedente no setor sucroalcooleiro. Disponível em: http://www.feagri.unicamp.br/energia/agre2004/Fscommand/PDF/Agrener/Trabalho\%2 0112.pdf . Acesso em: 07 mar. 2008.

CONEJERO, M. A. Marketing de Créditos de Carbono: um estudo exploratório. Dissertação (Mestrado). Instituição: Universidade de São Paulo (USP). Disponível em: http://www.teses.usp.br/teses/disponiveis/96/96132/tde-05072006-122457/ . Acesso em: 06 mai 2008.

CONEJERO, M. A.; NEVES, M. F. Gestão de créditos de carbono: um estudo multicasos. Disponível em:

http://www.pensa.org.br/anexos/biblioteca/1712008152515 Gest\%C3\%A3odecr\%C3\% A9ditosdecarbonoumestudomulticasos.pdf. . Acesso em: 07 ago. 2008.

DELGADO, M. F. Protocolo de Quioto: uma visão administrativa do mercado de credito de carbono. Disponível em: http://www.ead.fea.usp.br/Semead/8semead/resultado/an resumo.asp?cod trabalho=18 6. Acesso em: 05 jun. 2008. 
FREITAS, E. de. Protocolo de Kyoto. Brasil Escola. Disponível em:

http://www.brasilescola.com/geografia/protocolo-kyoto.htm . Acesso em: 07 mai 2008.

LECOCQ, F.; CAPOOR, K. State and trends of the carbon market 2005. PCFplus Research, World Bank, May, 2005. Disponível em: http://www.carbonfinance.org/ . Acesso em: 30 jul. 2008.

LEME, R. M.; CUNHA, K. B. D.; WALTER, A. Adicionalidade em Projetos de MDL e a Co-geração no Setor Sucroalcooleiro Brasileiro. Disponível em: http://www.feagri.unicamp.br/energia/agre2004/Fscommand/PDF/Agrener/Trabalho\%2 0109.pdf. . Acesso em: 30 jul. 2008.

MACEDO, I. C. Geração de energia elétrica a partir de biomassa no Brasil: situação atual, oportunidades e desenvolvimento. Relatório para o MCT, Brasília, 2001.

MOREIRA, H. M.; GIOMETTI, A. B. D. R. O Protocolo de Quioto e as Possibilidades de Inserção do Brasil no Mecanismo de Desenvolvimento Limpo por meio de Projetos em Energia Limpa. Disponível em: http://publique.rdc.pucrio.br/contextointernacional/cgi/cgilua.exe/sys/start.htm?infoid=464\&sid=66. Acesso em: 07 jul. 2008.

NASCIMENTO, R. D. S. Contabilidade: contabilidade e o mecanismo de desenvolvimento limpo: desenvolvimento sustentável. Disponível em: http://www.netlegis.com.br/fiscolegis/index.jsp?arquivo=detalhesFiscolegis.jsp\&codb= 7\&cod=15565. Acesso em: 06 nov. 2008.

OBSERVATORIO DO CLIMA (Brasil). Critérios de Sustentabilidade para Projetos de MDL no Brasil. Disponível em:

http://www.clima.org.br/arquivos/OC Criterio\%20Sustentabilidade.pdf . Acesso em: 06 mai 2008 .

PIVA, L. H.; BAITELO, R. Política Nacional de Clima: uma necessidade conveniente.

Boletim da Sociedade Brasileira de Economia Ecológica: Disponível em: http://www.ecoeco.org.br/pdf/boletimecoeco16.pdf . Acesso em: 04 jun. 2008.

RIBEIRO, W. C. Geração energética e inclusão social no Brasil. Boletim da Sociedade Brasileira de Economia Ecológica: Disponível em: http://www.ecoeco.org.br/pdf/boletimecoeco16.pdf . Acesso em: 04 jun. 2008.

RODRIGUES, D.; ORTIZ, L.. Em direção à sustentabilidade da produção de etanol de cana de açúcar no Brasil. Disponível em:

http://www.vitaecivilis.org.br/anexos/etanol_sustentabilidade.pdf. . Acesso em: 15 jul. 2008 .

SANTOS, A. L. D. Setor sucroalcooleiro: Conjuntura e perspectiva. Analise conjuntural, v.27 n 7-8 julho/agosto 2005. Disponível em:

http://www.ipardes.gov.br/pdf/bol_ana_conjuntural/bol_27_4g.zip. . Acesso em: 07 mai 2008.

YIN, R. K. Estudos de caso. São Paulo: Bookman, 2005. 


\section{Anexos}

\section{Questionário de pesquisa de campo sobre o tema:}

Oportunidades e Ameaças do mercado de crédito de carbono para as usinas sucroalcooleiras do Brasil.

1- Quais as oportunidades e quais as ameaças encontradas durante o período de integração da empresa no mercado financeiro? Como se encontra o atual mercado?

2- Com a queda no preço do petróleo, e o alavancamento do consumo do etanol, além do surgimento de propostas de energias renováveis; acha que a co-geraçao através do bagaço da cana, afeta de maneira positiva as transações empresariais? Se estende para o comércio internacional?

3- Qual é a linha de base da indústria sucroalcooleira referente ao mercado de crédito de carbono?

4- Atualmente qual é o volume de crédito de carbono gerado pelos projetos do setor sucroalcooleiro? Descreva.

5- Qual é o potencial de mercado de crédito de carbono das usinas de cana de açúcar no Brasil? E quais sãos as suas vantagens e desvantagens encontradas para o setor?

6- Qual o parâmetro de atuação do setor Sucroalcooleiro atualmente em questões estratégias de comercialização, ou seja, atuação no mercado de Kyoto ou no mercado Voluntário? Qual é o mercado de maior atuação? E por quê?

7- Quais são as perspectivas futuras das usinas de cana de açúcar referente ao Pós Kyoto, ou seja, referente ao término do primeiro período de contrato em 2012?

8- Quais são os custos referentes a implementação dos projetos a serem inseridos pelas empresas do setor?

9- Hoje quanto é negociado a Tonelada de $\mathrm{CO} 2$ equivalente pelas empresas do setor? $\mathrm{E}$ quais são as projeções para o futuro quanto ao preço das negociações?

10- Qual é o volume de créditos de carbono negociados atualmente pelas indústrias sucroalcooleiras e quais as perspectivas futuras?

11- Quais são as fragilidades encontradas pelo setor sucroalcooleiro no mercado de crédito de carbono? 
